\title{
Research on the Hybrid Audio-Lingual Model in College English Teaching with the Support of Mobile Technology
}

\author{
Yan Yan \\ School of Foreign Studies, Xi'an University, Xi'an, 710065, China. \\ irene009@126.com
}

Keywords: Teaching model; Mobile technology; Mobile learning; Hybrid teaching model

\begin{abstract}
With the increasingly frequent of international communication, the development of our country and the society has put forward a higher requirement to the college students' English capacity. The College English Curriculum Requirements revised in 2007, had clearly pointed out that we must strengthen students' English capacity, especially to strengthen the training of listening and speaking ability, cultivate the applied-talents with the self-learning ability. This paper proposes and demonstrates the topic of using mobile technology-based modern education technology to construct a hybrid teaching model of listening and speaking, and the purpose is to create a good environment for training students' English listening and speaking ability through the hybrid teaching model.
\end{abstract}

\section{INTRODUCTION}

It has a long time for our country college non-English major teaching using the pattern of intensive reading, but it neglects the cultivation of students' listening and speaking ability. So when students need to communicate in English someday in their life or work, they will find they can't achieve a good effect. Nowadays, this phenomenon has changed, with the rapid development of information technology, the deep integration of information technology and English curriculum has become the core of the revolution of current English teaching. So how to construct a listening and speaking teaching model in line with the characteristics and laws of English curriculum and how to cultivate students' English communicative competence have become the major issue we are facing now. However, with the rapid development of mobile technology, it has provided a new opportunity for the revolution of English teaching model. Because the mobile technology support learners using mobile devices to study at anytime and anywhere, apart from this, the mobile technology has a unparalleled advantage in extending learning time and space, enriching the interactive of learning, improving the efficiency of learning and so on.

\section{THE THEORETICAL BASIS FOR ENGLISH TEACHING IN LISTENING AND SPEAKING}

Under the guidance of different language learning theories, different language teaching methods also produced. In English listening and speaking teaching, there have two influential theories; they are second language acquisition theory and situated cognition and learning theory. These two theories can provide theoretical guidance for constructing a hybrid audio-lingual teaching model of college English teaching supported by mobile technology.

\section{A. Second Language Acquisition Theory}

Second language acquisition theory is proposed based on the research of the process and the law of the second language learning. Although this theory can't be directly used to solve practical problems in the foreign language classroom, it has a certain sense of inspiration and guidance for the foreign language teaching. Language is a reflection of human cognitive ability, and this point has become the consensus of researchers from different disciplines, thus the relationship between cognitive and language has become the research focus of the second language acquisition theory.

As far as time concerned, the development of second language acquisition theory is divided into two factions, they are cognitive psychology based theory and social culture theory based. Wherein the cognitive psychology based theory contains input hypothesis, interaction hypothesis and output 
hypothesis, which stressed that the accumulation of knowledge is the key to second language acquisition, and it is considered that the acceleration of sufficient language input, interaction and language output can improve students' English listening and speaking skills. However, the social culture theory based, represented by Vygotsky, considered that the second language acquisition focusing on participation, and the interactive activities that students take part in is also a learning process. So pay attention to increase meaningful interaction in teaching can let students truly involved in learning, rather than accepting learning. Based on these two theories, envisage the using of educational technology to encourage students to continue to participate in communication and interaction of oral English is of great significance for improving the effect, effectiveness and efficiency of oral English teaching.

\section{B. Situated Cognition and Learning Theory}

Situated cognition and learning theory was first used by Resniek in Both Inside and Outside of School Learning,, published in 1987, during his inaugural address of American Education Research Association. After that, Brown, Collins and Duguid published the Situated Cognition and the Culture of Learning., they elaborated the situated cognition and learning theory completely. During the same time period, these anthropologists represented by Lave researched the situated cognition and learning from the perspective of anthropological. With the emergence of situated learning in the cognitive domain, researchers elevated the human's study on learning to a new level.

Situated cognition emphasizes considering knowledge as a useful tool, and tries to promote students' cultural adaptation through practical activities and social interaction; situated learning considers that knowledge is an activity based on social context, rather than a specific abstract object; knowledge is an interactive state constructed during the interaction between the individual and the environment, rather than a fact; and the knowledge is a coordinated series of human behavior, and the ability to adapt to the changing and developing environment.

Currently, the rapid development of mobile communication technology makes it possible to obtain any knowledge at anytime and anywhere, this will improve the quality of learning activities greatly. Thus, to the situated cognition and learning, mobile learning provides lots of technical support, and on the contrary, the situated cognition and learning theory provides theoretical basis for the mobile learning, apart from this, the situated cognition and learning theory provides us with a unique perspective of learning and teaching. These learning and teaching concepts proposed by the situational cognition theory have a huge revelation to the cultivation of students' practical English skills.

\section{RESEARCH ON THE MOBILE LEARNING AND MOBILE LANGUAGE LEARNING}

Mobile learning as a new way of learning can be widely used, and so far, there is no a clear definition, this is because the mobile learning involves many factors. Experts and scholars at home or abroad understand and elaborate the mobile learning from different point of view. Generally speaking, the definition of mobile learning can be given respectively both from the aspect of emphasizing on technology and from the aspect of emphasizing on learning method.

\section{A. Key Technology Supporting Mobile Learning}

The technology that supports the mobile learning mainly includes two parts; they are mobile computing terminals and mobile communication technology.

1) Mobile terminal computing devices

When choosing a terminal computing device that will be used in the mobile learning, we should choose according to the actual situation of the mobile learning activities that we are carrying out and the network access methods supported by the terminal. Apart from these, many other important factors should also be taken into consideration, such as whether it is smart or not, the size of the screen, the hardware parameters and so on. In table 1 below, some information about these often used devices have been given out. 
TABLE 1

\begin{tabular}{|c|c|c|c|c|}
\hline Device Name & Portability & Screen & Cost & $\begin{array}{c}\text { Operating } \\
\text { System }\end{array}$ \\
\hline Mobile phone & High & $\begin{array}{c}\text { Small }<3 \\
\text { Inch }\end{array}$ & Low & None \\
\hline Smart phone & High & $\begin{array}{c}\text { Small < } \\
\text { 5Inch }\end{array}$ & Middle & $\begin{array}{l}\text { Symbian, } \\
\text { Windows, } \\
\text { Palm, } \\
\text { Android, } \\
\text { IPhoneOS }\end{array}$ \\
\hline (iPAD)/UMPC & & $\begin{array}{l}\text { Middle } \leqslant \\
7 \text { Inch }\end{array}$ & & Linux \\
\hline MP3 & High & $\begin{array}{l}\text { Small 1-2 } \\
\text { Inch }\end{array}$ & Low & None \\
\hline MP4,MP5 & High & $\begin{array}{l}\text { Small 2-5 } \\
\text { Inch }\end{array}$ & Low & None \\
\hline
\end{tabular}

\section{2) Mobile Communication Technology}

Mobile communication technology is a key technology to support the mobile learning, including two systems of wireless communication and cellular mobile communication, this can enable the mobile learners to acquire learning resources and to communicate with others. For the mobile learning, setting up the communicating environment is a prerequisite, but different mobile learning scenarios and different learning activities depend on different network environments, and the way of deployment that applied is also different.

\section{B. Mobile Technology Assists Language Learning Research}

With the continuous development of mobile technology, many features that match the demand of foreign language teaching turn out continuously. This makes some related research warming gradually, and an independent field of study also formed, that is the Mobile Assisted Language Learning (MALL for short). Actually, the application of educational technology to promote foreign language teaching should take full account of the combination of technical and linguistic characteristics, and for language learning, each technology has its own particular strengths. Therefore, apply the mobile learning to foreign language learning is to use some certain characteristics of mobile technology to realize the full needs of foreign language teaching, and by this, learners can study and improve their study efficiency much more convenient.

\section{CONSTRUCTION OF COLLEGE ENGLISH HYBRID AUDIO-LINGUAL TEACHING MODEL SUPPORTED BY MOBILE TECHNOLOGY}

\section{A. Concept of Teaching Model}

Although the concept of teaching model has existed for a long time, it truly becomes an independent educational research category usually started from the beginning of Joyce and Weil's research in 1999. Presently, there are a lot of definitions for some related teaching model, such as Joyce and Weil had given in their monograph - Models of Teaching, like this, teaching model is a plan or a pattern to constitute course( long time learning process), select teaching material and guide the teaching activities in a classroom or other environment.

\section{B. Design of College English Hybrid Audio-Lingual Teaching Model Supported by Mobile Technology}

Cod has said, "Effective language teaching should adapt to the natural process rather than go against to it, should contribute to learning and promote learning rather than hinder learning, should let the teachers and teaching materials adapt to students rather than let students adapt themselves to the teachers and teaching materials." As a practical lesson, English teaching activities should be bilateral activities between students and teachers, the students should be the subject of learning and the internal of teaching process, so whether the learning is successful or failed, it is determined by students themselves. Therefore, in this paper, the author constructs a college English hybrid 
audio-lingual teaching model supported by mobile technology.

1) General idea

"College English hybrid audio-lingual teaching model supported by mobile technology" is a hybrid teaching model that is based on the interaction between the extracurricular autonomous learning and curricular interactive learning. Generally speaking, this model can be divided into three phases, previewing before class, exercising in class, and exploring after class, so as to achieve the mixture of the following five dimensions: a) mixture of the formal learning methods in class and the informal learning methods after class; b) mixture of the teachers' teaching and students' independent learning in class; c) mixture of teacher-directed and student-centered in class; d) mixture of the traditional media and new media during the teaching and learning process; e) mixture of the English language knowledge and the English listening and speaking skills among the teaching content.

2) Structural model of the teaching model

As shown in the Fig 4.1, the whole structure is made up of three parts, and these three parts formed a cycle system. Each part has an influence on its successive part.

Fig 4.1 structural model of the teaching model

\section{Strategy for the teaching model}

Although scholars at home and abroad have different viewpoints on the classification of the English learning strategies, no agreement has been achieved so far. However, it is agreed that even the same strategy, different learners or in different occasions, a different using effect will be achieved. For the learning strategy itself, it can't be moderate. Therefore, in the training process of strategy, we should neither generally take all strategies into the training range, nor choose some of the strategies for training as one's pleases. When we choose an appropriate strategy for training, we should take these factors into consideration, such as who is the learner, what is the learning content, how about the learning situation and so on. The content of the strategies that we choose should be consistent with students' needs, and can help students solve the main problems existing in their learning, so as to stimulate their interest in learning English, and excavate their potential motivation.

Under the hybrid audio-lingual teaching model, decentralized training methods are advocated, combine with the content of the knowledge unit, and then the appropriate audio-lingual teaching materials should be chosen to express the goal and the value of strategies the teacher uses to the learners directly with a clear training method. It is more conducive to deepen learners' awareness of using strategy. During teachers' lecture and demonstration, present and elaborate the using of listening and speaking strategies based on students' understanding, applies some related strategies to walk through language knowledge by some interactive activities. Finally, in the after-school cooperative task, the students transfer the strategies they have learned to a new learning task.

\section{SUMMARY}

It is the responsibility for our educators to teach with the educational technology. After analyzing the factors that affect college students' listening and speaking ability, this study attempts to take the advantage of the mixture of mobile technology and traditional technology to improve the existing adverse conditions. By this, a favorable environment can be created, and it is of great significance for training students' listening and speaking ability.

\section{References}

[1]Cheng J Y. Hiroaki Ogata and Yoneo Yano. Ubiquitous Learning System for Japanese Polite Expressions. Proceedings of the 3rd IEEE International Workshop on Wireless and Mobile Technologies in Education (WMTE 2005).

[2]Gardner, R. C., \&Mac Intyre P. D. On the Measurement of Affective Variables in Second Language Learning Language Learning. 1993. 43. 
[3]Hiroaki Ogata, Gan Li Hui and Chengjiu Yin. LOCH:Supporting Mobile Language Learning Outside Classrooms [J].Int. J. Mobile Learning and Organization, Vol. 2, No. 3， 2008.

[4]Newhouse, C. P., Williams, P. J. and Pearson, J. Supporting Mobile Education for Pre-service Teachers[J]. Educational Technology, 2006(22).

[5]Wood, D., J. Bruner, and G. Ross. The Role of Tutoring in Problem-solving [J].Journal of Child Psychology and Psychiatry, 1976, 17(2):89-100. 